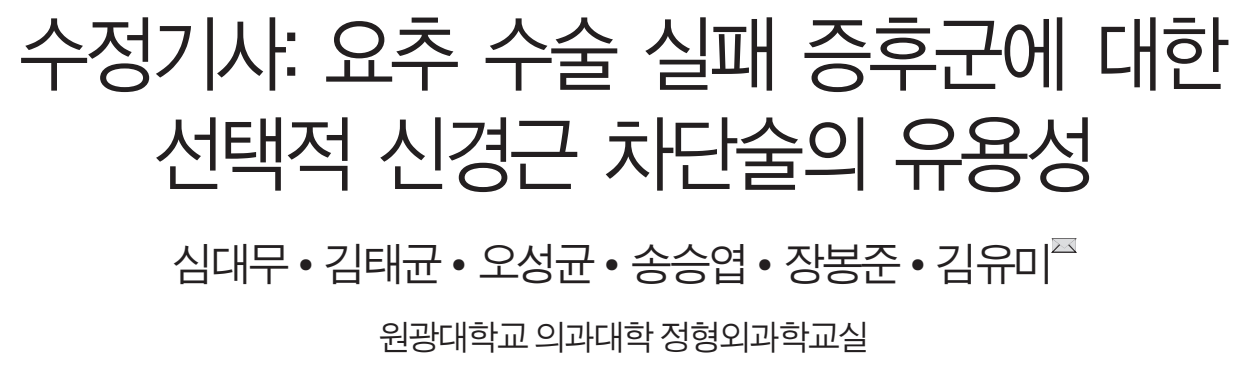

\title{
Corrigendum: The Usefulness of Selective Nerve Root Block for Failed Back Surgery Syndrome
}

Dae Moo Shim, M.D., Tae Kyun Kim, M.D., Sung Kyun Oh, M.D., Seung Yeop Song, M.D., Bong Jun Jang, M.D., and Yu Mi Kim, M.D.

Department of Orthopaedic Surgery, Wonkwang University School of Medicine, Iksan, Korea

Korean Orthop Assoc 2017; 52: 185-191 • https://doi.org/10.4055/jkoa.2017.52.2.185

본 학술지에 게재된 상기 논문은 저자의 요청에 따라 아래와 같이 연구비 사사문구를 추가합니다.

*This research was supported by grant from Wonkwang University, 2017.

*본 연구는 2017년 원광대학교 연구비 지원을 받아 이루어졌음. 